\title{
Associations Between Bipedal Stance Stability and Locomotor Stability Following a Trip in Unilateral Vestibulopathy
}

Citation for published version (APA):

McCrum, C., Eysel-Gosepath, K., Epro, G., Meijer, K., Savelberg, H. H. C. M., Brueggemann, G-P., \& Karamanidis, K. (2017). Associations Between Bipedal Stance Stability and Locomotor Stability Following a Trip in Unilateral Vestibulopathy. Journal of Applied Biomechanics, 33(2), 112-117. https://doi.org/10.1123/jab.2016-0004

Document status and date:

Published: 01/04/2017

DOI:

10.1123/jab.2016-0004

Document Version:

Publisher's PDF, also known as Version of record

Document license:

Taverne

Please check the document version of this publication:

- A submitted manuscript is the version of the article upon submission and before peer-review. There can be important differences between the submitted version and the official published version of record.

People interested in the research are advised to contact the author for the final version of the publication, or visit the DOI to the publisher's website.

- The final author version and the galley proof are versions of the publication after peer review.

- The final published version features the final layout of the paper including the volume, issue and page numbers.

Link to publication

\footnotetext{
General rights rights.

- You may freely distribute the URL identifying the publication in the public portal. please follow below link for the End User Agreement:

www.umlib.nl/taverne-license

Take down policy

If you believe that this document breaches copyright please contact us at:

repository@maastrichtuniversity.nl

providing details and we will investigate your claim.
}

Copyright and moral rights for the publications made accessible in the public portal are retained by the authors and/or other copyright owners and it is a condition of accessing publications that users recognise and abide by the legal requirements associated with these

- Users may download and print one copy of any publication from the public portal for the purpose of private study or research.

- You may not further distribute the material or use it for any profit-making activity or commercial gain

If the publication is distributed under the terms of Article $25 \mathrm{fa}$ of the Dutch Copyright Act, indicated by the "Taverne" license above, 


\title{
Associations Between Bipedal Stance Stability and Locomotor Stability Following a Trip in Unilateral Vestibulopathy
}

\author{
Christopher McCrum,, ${ }^{1,2}$ Katrin Eysel-Gosepath, ${ }^{3}$ Gaspar Epro, ${ }^{2,4}$ Kenneth Meijer, ${ }^{1}$ \\ Hans H.C.M. Savelberg, ${ }^{1}$ Gert-Peter Brüggemann, ${ }^{2,5}$ and Kiros Karamanidis ${ }^{2,4}$ \\ ${ }^{1}$ Maastricht University Medical Centre+; ${ }^{2}$ German Sport University Cologne; ${ }^{3}$ Heinrich Heine University of Düsseldorf; \\ ${ }^{4}$ London South Bank University; ${ }^{5}$ University of Cologne
}

\begin{abstract}
Posturography is used to assess balance in clinical settings, but its relationship to gait stability is unclear. We assessed if dynamic gait stability is associated with standing balance in 12 patients with unilateral vestibulopathy. Participants were unexpectedly tripped during treadmill walking and the change in the margin of stability $\left(\mathrm{MoS}_{\text {change }}\right)$ and base of support $(\mathrm{BoS}$ change $)$ relative to nonperturbed walking was calculated for the perturbed and first recovery steps. The center of pressure (COP) path during 30-s stance with eyes open and closed, and the distance between the most anterior point of the COP and the anterior BoS boundary during forward leaning $\left(\mathrm{A}_{\text {Dist }}\right)$, were assessed using a force plate. Pearson correlations were conducted between the static and dynamic variables. The perturbation caused a large decrease in the BoS, leading to a decrease in MoS. One of 12 correlations was significant $\left(\mathrm{MoS}_{\text {change }}\right.$ at the perturbed step and $\mathrm{A}_{\text {Dist }} ; r=-.595, P=.041$; nonsignificant correlations: $\left..068 \leq P \leq .995\right)$. The results suggest that different control mechanisms may be involved in stance and gait stability, as a consistent relationship was not found. Therefore, posturography may be of limited use in predicting stability in dynamic situations.
\end{abstract}

Keywords: vestibular, dynamic gait stability, falls, balance, locomotion

Posturography assesses balance and postural sway through center of pressure (COP) measurements during stance and has been used in groups which have an increased falls risk, such as lower limb amputees, ${ }^{1}$ older adults, ${ }^{2,3}$ and vestibulopathy patients. ${ }^{4,5}$ Contributions of sensory systems to postural control can be estimated by disturbing vision, ${ }^{6}$ changing the support surface, ${ }^{7}$ or via Achilles tendon vibration. ${ }^{7-9}$ However, the majority of falls occur during ambulation, ${ }^{10-14}$ not static stance, which may be one reason why

McCrum is with NUTRIM School of Nutrition and Translational Research in Metabolism, Maastricht University Medical Centre+, Department of Human Movement Science, Maastricht, The Netherlands; and the Institute of Movement and Sport Gerontology, German Sport University Cologne, Cologne, Germany. Eysel-Gosepath is with the Department of Otolaryngology, Head and Neck Surgery, Heinrich Heine University of Düsseldorf, Düsseldorf, Germany. Epro is with the Institute of Movement and Sport Gerontology, German Sport University Cologne, Cologne, Germany; the Institute of Biomechanics and Orthopaedics, German Sport University Cologne, Cologne, Germany; and Sport and Exercise Science Research Centre, School of Applied Sciences, London South Bank University, London, UK. Meijer and Savelberg are with NUTRIM School of Nutrition and Translational Research in Metabolism, Maastricht University Medical Centre+, Department of Human Movement Science, Maastricht, The Netherlands. Brüggemann is with the Institute of Biomechanics and Orthopaedics, German Sport University Cologne, Cologne, Germany; and the Cologne Center for Musculoskeletal Biomechanics, Medical Faculty, University of Cologne, Cologne, Germany. Karamanidis is with the Institute of Movement and Sport Gerontology, German Sport University Cologne, Cologne, Germany; and Sport and Exercise Science Research Centre, School of Applied Sciences, London South Bank University, London, UK. Address author correspondence to Kiros Karamanidis at k.karamanidis@1sbu.ac.uk. posturography appears to be limited as a clinical test, rehabilitation tool, and falls risk assessment method. ${ }^{15}$

From a mechanical perspective, the vertical projection of the center of mass (CoM) is within the base of support (BoS) during bipedal stance and is controlled through anticipatory adjustments of the sensory and neuromuscular systems. However, in dynamic settings, the extrapolated CoM is often situated outside of the BoS and the CoM has a velocity and specific direction, and effective reactive postural adjustments (eg, by increasing BoS) are required to control stability. ${ }^{16-19}$ These differences may explain why posturography could not separate fallers from nonfallers in a slip recovery test during gait. ${ }^{20}$ Similarly, the maximum recoverable forward lean angle is not generally predicted by static posturography. ${ }^{21,22} \mathrm{How}-$ ever, such comparisons between static and dynamic tasks have not, to our knowledge, been conducted in subject groups with balance disorders. Vestibulopathy is associated with imbalance, dizziness and falls, ${ }^{23-26}$ and decreased motor performance, ${ }^{17,27,28}$ and therefore it is important to determine if posturography can provide some insight into gait stability issues seen in these patients.

In a recent study of our group, we reported that patients with unilateral peripheral vestibular disorder have a diminished ability to control and adapt their dynamic gait stability following unexpected trip perturbations while walking compared with healthy participants. ${ }^{17}$ Additionally, it has been well documented that various posturography methods can discriminate vestibular patients from healthy subjects. ${ }^{29-32}$ Given that both static and dynamic methods reveal differences between healthy and vestibulopathy groups, and that posturography can be easily and cheaply conducted, an assessment of the relationship between such tasks is needed to determine if posturography alone is sufficient to estimate dynamic gait stability. To address this, we collated previously collected data from the dynamic gait stability measurements ${ }^{17}$ and from posturography measurements conducted with the same patients. ${ }^{33}$ An explorative 
analysis was conducted to determine correlations between dynamic stability control following a trip and COP parameters during a forward leaning task and during quiet standing with the eyes open and closed. Based on previous results demonstrating a lack of relationship between static and dynamic stability tasks, ${ }^{20-22}$ we did not expect to find a consistent relationship between the dynamic stability parameters and the COP parameters during quiet standing, but we suspected that the forward lean task may reveal some correlations with the dynamic task due to the fact that the anterior limit of stability is more challenged in this task than during quiet standing.

\section{Methods}

For this explorative analysis, we pooled previously collected data of patients with unilateral peripheral vestibular disorder from 2 previous studies, the first involving a tripping while walking task ${ }^{17}$ and the second involving stance posturography tasks. ${ }^{33}$ For each parameter of interest (see below) we included all patients with data from each variable. In total, 12 patients were included, with age, height, and weight of 50.5 (5.4) years, $169.7(6.6) \mathrm{cm}$, and $72.5(9.6) \mathrm{kg}$, respectively (mean and SD). All patients were assessed for inclusion by an otolaryngologist to confirm their diagnoses. Further inclusion criteria were that participants did not exercise more than once per week and had no other health issues. The studies were approved by the ethical board of the university, the procedures were explained to the participants, and written informed consent was obtained in accordance with the Declaration of Helsinki.

Previous work has reported the effects of repeated trip perturbations on these subjects. ${ }^{17}$ Here, we consider only the impact of the first unexpected trip, to exclude the possibility of adaptation influencing the results and to analyze a more ecologically valid response to the trip perturbation. ${ }^{34}$ Full details on the trip perturbation device have been reported previously. ${ }^{17,35,36}$ Briefly, the tripping task was conducted during treadmill walking at $1.4 \mathrm{~m} \cdot \mathrm{s}^{-1}$ (pulsar 4.0, $\mathrm{h} / \mathrm{p} /$ cosmos, Nussdorf-Traunstein, Germany) using a custom built electronically driven magnet system to provide a trip perturbation. The perturbation consisted of a single unilateral resistance of $2.1 \mathrm{~kg}$ applied and removed unexpectedly to the right leg during the swing phase via a Teflon cable and ankle strap. Participants wore a safety harness connected to an overhead track during all trip recovery and posturography trials. Four to 7 days before the measurement session, all participants took part in a treadmill walking familiarization session, lasting approximately 30 minutes, to become accustomed to the treadmill walking conditions. On the day of the measurement, the session began with 5 minutes of walking to ensure participants were comfortable on the treadmill. The ankle strap was then attached to the right leg and participants walked for another 4 minutes to establish a baseline (about 20 seconds was recorded toward the end of this period to be used as a nonperturbed walking baseline). Directly following the baseline period, the perturbation was applied for the entire duration of the swing phase and was subsequently removed. Participants were not given a warning about the upcoming perturbation. An example of a typical recovery response to the perturbation from 1 participant can be seen in Figure 1.

To examine dynamic gait stability, we tracked a 12-segment, full kinematic model using 26 reflective markers (radius $16 \mathrm{~mm}$ ) recorded by an 8 camera $(120 \mathrm{~Hz})$ Vicon Nexus motion capture system. Segmental masses and locations were calculated based on the data of Dempster et al. ${ }^{37}$ The margin of stability (MoS) in the anteroposterior direction was calculated, as defined by Hof et $\mathrm{al}^{38}$ (see Figure 2), as the difference between the BoS anterior boundary (anteroposterior position of the toe marker) and the extrapolated $\mathrm{CoM}$ at the instant of foot touchdown (determined using tibia accelerometer data [ADXL250; Analog Devices, Norwood, MA, USA]) during baseline nonperturbed walking, and at touchdown of the perturbed step (PERT) and the first recovery step following the perturbation $\left(\mathrm{POST}_{1}\right)$. The extrapolated CoM was defined as follows:

$$
\text { Extrapolated CoM }=P_{C o M}+\frac{\left(V_{C o M}+\left|V_{B o S}\right|\right)}{\sqrt{g \cdot L^{-1}}},
$$

where $\mathrm{P}_{\mathrm{CoM}}$ is the horizontal (anteroposterior) component of the projection of the CoM to the ground, $\mathrm{V}_{\mathrm{CoM}}$ is the horizontal velocity of the CoM, $\mathrm{V}_{\mathrm{BoS}}$ is the average horizontal velocity of the foot markers during stance (approximately the treadmill belt speed), $g$ is gravitational acceleration, and $L$ is the pendulum length (the distance between the CoM and the center of the ankle joint in the sagittal plane). We focused here on these 2 steps as our previous work demonstrated the importance of the perturbed and first recovery step when recovering stability following such perturbations. ${ }^{17}$ Baseline values for MoS and BoS (BoS defined as the anteroposterior distance between the left and right toe markers) were calculated at foot touchdown by averaging 12 consecutive steps of nonperturbed walking. To account for individual differences in walking stability, the change in the MoS and BoS relative to baseline nonperturbed walking at PERT and $\mathrm{POST}_{1}$ was used for this study $\left(\mathrm{MoS}_{\text {change }}\right.$ and $\mathrm{BoS}_{\text {change, }}$, respectively), where negative $\mathrm{MoS}_{\text {change }}$ and $\mathrm{BoS}_{\text {change }}$ values represent lower stability and smaller BoS, respectively, relative to baseline nonperturbed walking.

Our previous study of stance stability assessed many variables from different sensory conditions in these patients. ${ }^{33}$ In the current study, we include 3 variables and 2 tasks that are

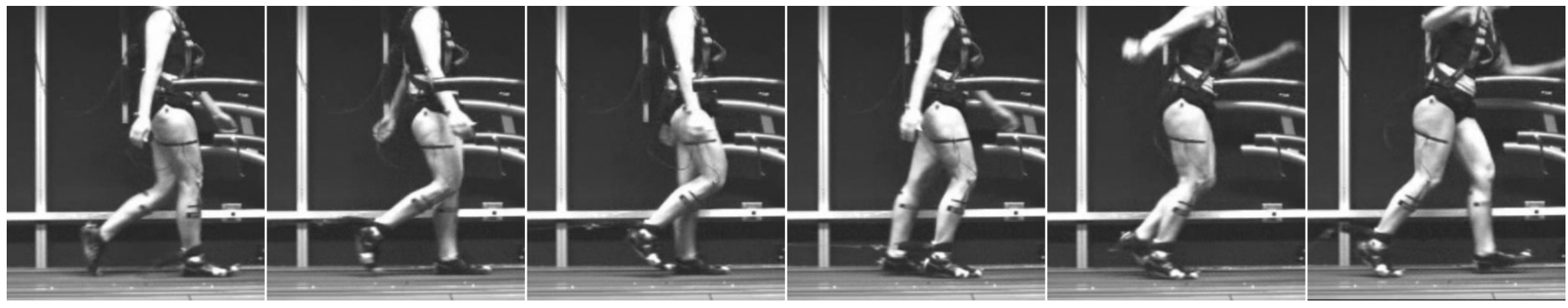

Figure 1 - Example of a typical recovery response to the trip perturbation in one participant. The perturbation adds resistance to the swing phase of the right leg, leading to a reduction in the base of support at foot touchdown. This causes a more anterior position and higher velocity of the center of mass at touchdown, relative to nonperturbed walking. In response, an increased base of support is required in the following recovery step to maintain gait stability. 


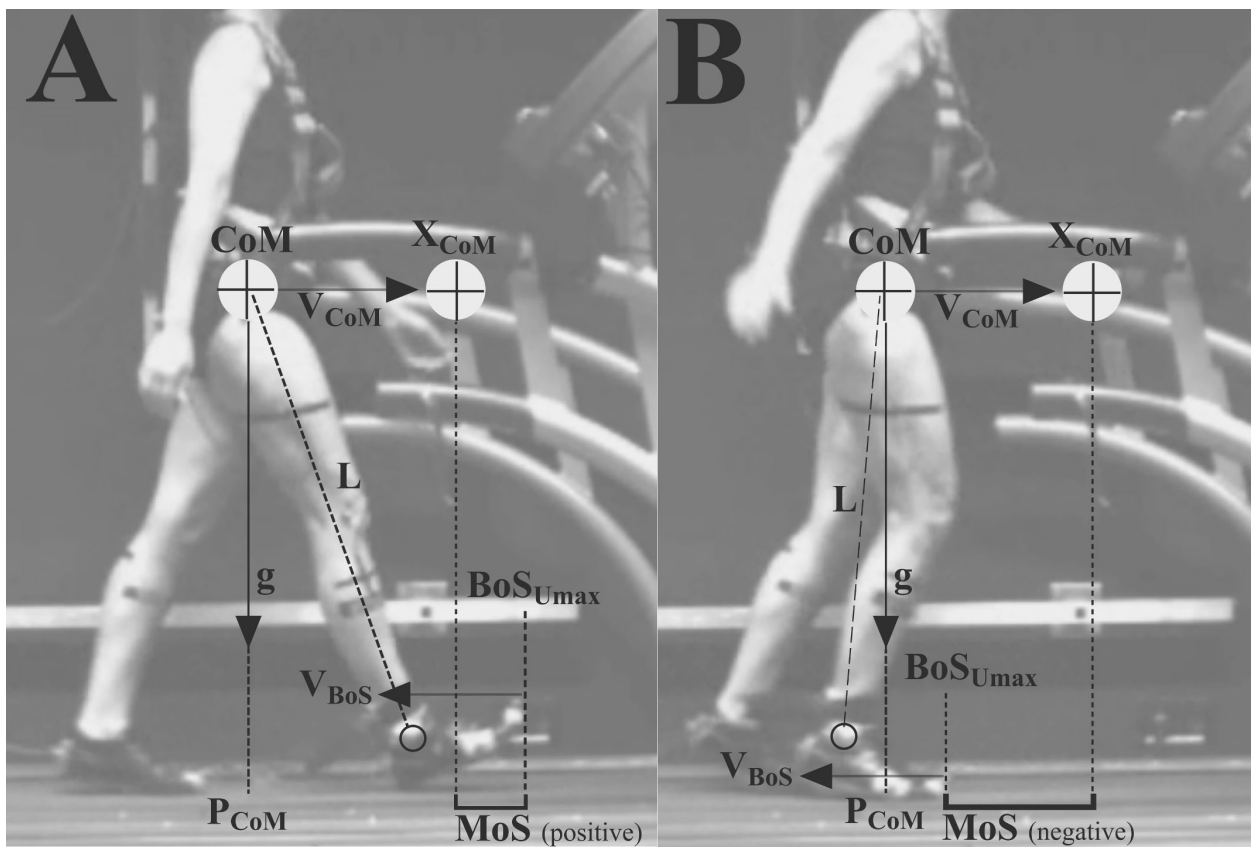

Figure 2 - Schematic diagram of the inverted pendulum model during locomotion. ${ }^{38} \mathrm{P}_{\mathrm{CoM}}$ represents the horizontal (anterior-posterior) component of the projection of the center of mass $(\mathrm{CoM})$ to the ground, $\mathrm{V}_{\mathrm{CoM}}$ is the anterior-posterior velocity of the CoM, $\mathrm{V}_{\mathrm{BoS}}$ is the average horizontal velocity of the foot markers during stance (approximately the treadmill belt speed), $g$ is acceleration due to gravity and $\mathrm{L}$ is the pendulum length (ie, distance between the CoM and the center of the ankle joint in the sagittal plane). Margin of stability (MoS) in the anterior direction is calculated at foot touchdown as the difference between the anterior boundary of the base of support $\left(\mathrm{BoS}_{\mathrm{Umax}}\right)$ and the extrapolated center of mass $\left(\mathrm{X}_{\mathrm{CoM}}\right)$. A stable body configuration is indicated by positive MoS values (A), whereas an unstable body configuration is indicated by negative margin of stability values (B), where additional motor actions, such as stepping, are required to preserve stability and to avoid a fall.

conducted in clinical settings and provide information on general stance stability with and without visual sensory information, and stability control near the anterior limit of stability. Participants stood on a custom made strain gauge force plate which was used to measure (at $1000 \mathrm{~Hz}$ ) the position of the COP during forward leaning and upright standing tasks. Participants stood barefoot with their feet at pelvic width and with their heels on a marked line on the platform. The positions of both feet were marked with a line on the force plate to transform the coordinates of the anterior and posterior boundaries of the $\mathrm{BoS}$ into the coordinate system of the force plate. In this way, the position of the COP could be calculated in relation to the boundaries of the BoS. For the leaning task, participants were instructed to lean as far forward as possible without moving joints other than the ankles. The task was repeated 3 times, with the trial showing the least difference between the most anterior position of the COP under the feet and the anterior boundary of the $\mathrm{BoS}$ (the line connecting left and right metatarsal 5) being used for each subject $\left(\mathrm{A}_{\text {Dist }}\right)$. Participants were then asked to stand as still as possible on the platform for 3 trials, under both eyes open and eyes closed conditions, each with a time frame of 30 seconds. For the eyes closed condition, participants wore blackout glasses (custom made) to ensure that there was no visual sensory input during this condition. A Hamming low-pass filter with a cut off frequency of $5 \mathrm{~Hz}$ was used to remove high frequency noise and eliminate sampling error. Postural stability was assessed by the total excursion distance of the $\mathrm{COP}\left(\mathrm{COP}_{\text {Path }}\right)$ over the 30-second analysis window. The average values of the COP parameters from the 3 trials for each participant were used in the analysis.

Pearson correlations were used to analyze the relationships between the posturography measures $\left(A_{\text {Dist }}\right.$, eyes open and eyes closed $\left.\mathrm{COP}_{\text {Path }}\right)$ and $\mathrm{MoS}$ and $\mathrm{BoS}$ values of the trip recovery task. Twelve and 8 participants' data were included for the $A_{\text {Dist }}$ and $\mathrm{COP}_{\text {Path }}$ correlation analyses, respectively. The level of significance for all tests was set at $\alpha=.05$. The distribution normality of the results was checked before applying statistical analysis using the Shapiro-Wilk test, which revealed normal distributions for all parameters $(P>.05)$. GraphPad Prism version 7.00 software (GraphPad Software Inc., La Jolla, California, USA) was used for the statistical analysis. All results are presented as mean and standard deviation.

\section{Results}

The perturbation resulted in large changes in both the BoS and $\mathrm{MoS}$. Changes in $\mathrm{BoS}$ and $\mathrm{MoS}$ relative to baseline at touchdown of the perturbed step and first recovery step are presented in Figure 3. The perturbation caused a large decrease in the $\mathrm{BoS}$ at touchdown of the perturbed step, leading to a decrease in MoS (Figure 3). A larger step was then taken in an attempt to control stability (see BoS at $\mathrm{POST}_{1}$ in Figure 3) but, due to the forward velocity induced by the trip, the MoS did not return to baseline level (Figure 3).

Consistent correlations between the posturography and dynamic stability parameters were not found. The 3 posturography tasks yielded results of $5.96(1.6) \mathrm{cm}, 21.17(5.87) \mathrm{cm}$, and 30.98 (9.54) $\mathrm{cm}$ for $\mathrm{A}_{\text {Dist }}$, eyes open and eyes closed $\mathrm{COP}_{\text {Path }}$, respectively. The correlation analyses revealed a significant negative correlation between $\mathrm{A}_{\text {Dist }}$ and $\mathrm{MoS}_{\text {change }} \mathrm{PERT}(r=-.595, P=.041$; Figure 4). The other 11 correlation coefficients were not significant (see all $r$ and $P$ values in Figure 4). 

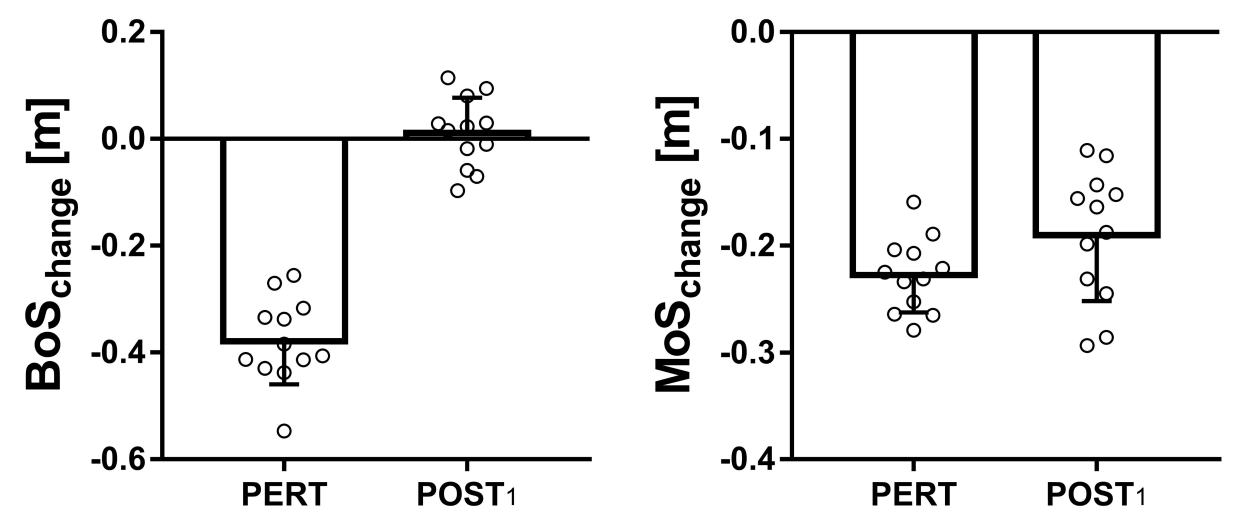

Figure 3 - Change relative to baseline nonperturbed walking in base of support $(\mathrm{BoS})$ and margin of stability $(\mathrm{MoS})$ at touchdown of the perturbed step (PERT) and the first recovery step (POST 1 ) for 12 patients with unilateral vestibulopathy (mean, SD, and individual data points).
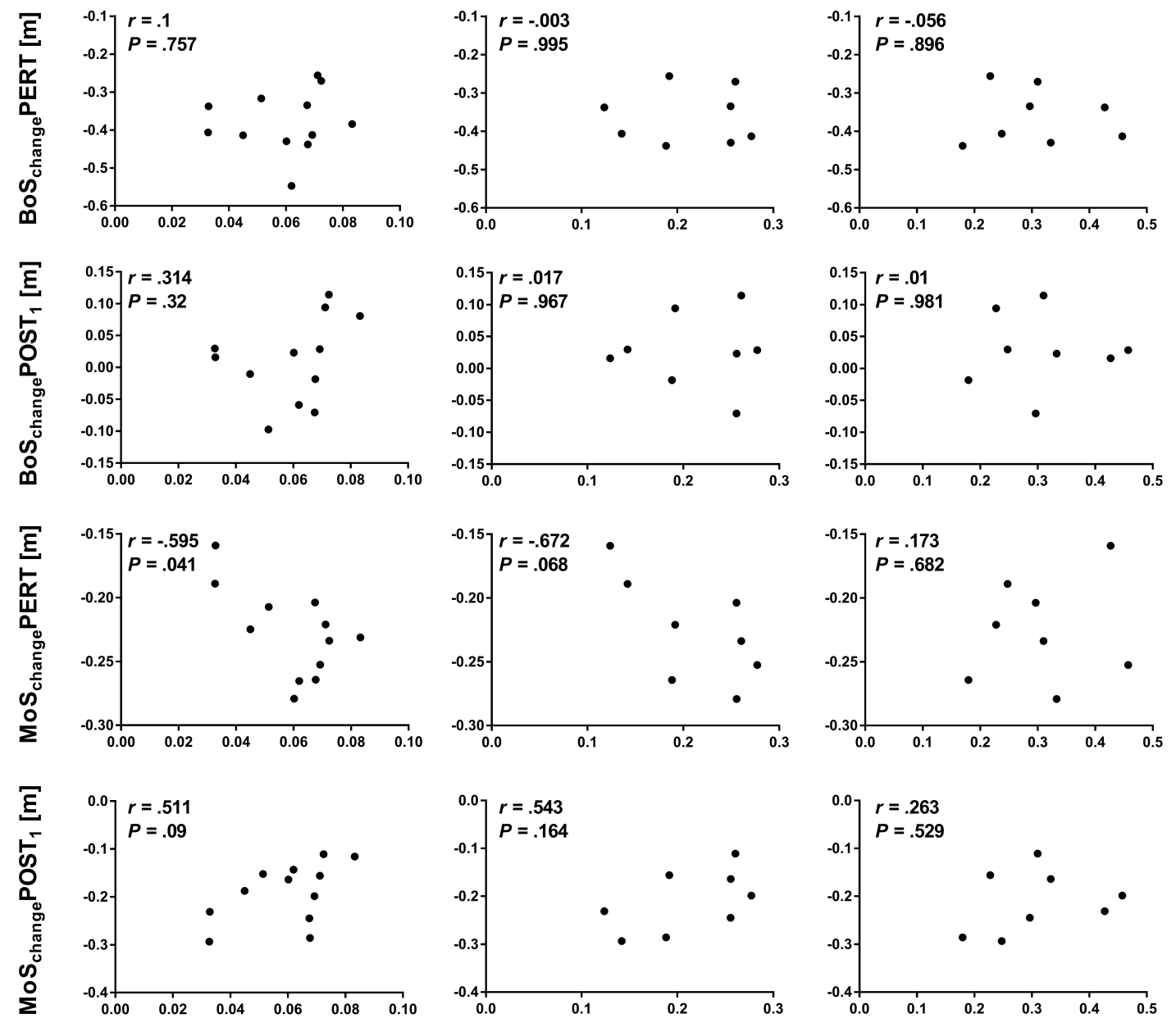

$A_{\text {Dist }}[\mathrm{m}]$

EO COP Path $[\mathrm{m}]$

EC COP Path $[\mathrm{m}]$

Figure 4 - Pearson correlation coefficients $(r)$ between the static and dynamic stability tasks. Twelve patients with unilateral vestibulopathy were included for the $\mathrm{A}_{\text {Dist }}$ correlations and 8 patients were included for the eyes open (EO) and eyes closed (EC) $\mathrm{COP}_{\text {Path }} \mathrm{Correlations} \mathrm{BoS} \mathrm{S}_{\text {change }} \mathrm{PERT}$ and $\mathrm{BoS}_{\text {change }} \mathrm{POST}_{1}$ : Change in the base of support relative to baseline nonperturbed walking at touchdown of the perturbed and first recovery steps, respectively. $\mathrm{MoS}_{\text {change }} \mathrm{PERT}$ and $\mathrm{MoS}_{\text {change }} \mathrm{POST}_{1}$ : Change in the margin of stability relative to baseline nonperturbed walking at touchdown of the perturbed and first recovery steps, respectively. $\mathrm{A}_{\text {Dist }}$ : Distance between the most anterior point of the COP during the forward leaning task and the anterior boundary of the base of support (the line connecting left and right metatarsal 5). EO and EC COP Path: Total path length of the center of pressure trajectory during 30 seconds of quiet stance with eyes open and closed, respectively. 


\section{Discussion}

The current study aimed to determine if balance maintenance during quiet stance and dynamic gait stability recovery performance were related in patients with unilateral peripheral vestibular disorder. Only one significant correlation was found out of 12 (Figure 4), suggesting that performance during static stability tasks is not closely related with stability in dynamic situations. This may be particularly relevant for clinical settings where assessment of static stance, but not dynamic gait stability, is conducted in patient groups with an increased falls risk.

The significant negative correlation between $\mathrm{A}_{\text {Dist }}$ and MoSchange PERT means that, in these participants, the ability to bring the COP closer to the anterior boundary of the BoS during forward leaning was associated with a less negative $\mathrm{MoS}$ at touchdown of the tripped step during walking. It could be speculated that a more anterior limit of stability was the underlying mechanism for this finding, as this could facilitate both a more anterior COP position during leaning, as well as the ability to apply force to the ground more anteriorly following the perturbation. Similarly, this could also be related to the ability to control CoM velocity in the anterior direction, although this is perhaps less likely, due to the large difference in movement speed of the tasks. In either case, this result suggests that such an anterior leaning task may have some value in assessing the ability to control stability in the anterior direction. However, given the lack of significant correlations in general, the use of posturography tasks for the purpose of estimating stability in dynamic settings is not well supported by our results. This agrees with previous studies in other populations using forward lean and release or slip perturbations. ${ }^{20-22}$ That being said, one limitation of this study was that it was not powered to test a null hypothesis such as that no correlations between the tasks would be found and therefore, it may be that with a larger sample size, more significant correlations could have been detected. We do not think that this is likely, however, as when we included age-, height-, and weight-matched healthy subjects in the analysis (data not shown), thereby artificially increasing the variation of performance, this did not greatly change the results.

The lack of association between the posturography and trip recovery outcome measures may be due to differences in the governing control strategies and mechanisms of stability associated with the tasks. Posturography during quiet stance assesses the ability to keep the vertical projection of the body's CoM within the $\mathrm{BoS}$, principally by using anticipatory adjustments. In contrast, the ability to regain dynamic stability after tripping or slipping where the extrapolated CoM is located outside of the BoS is governed principally by reactive postural adjustments. ${ }^{18,19} \mathrm{Here}$, a key factor in preventing a fall is the ability to take a large recovery step to lengthen the BoS and increase the MoS. ${ }^{16-18}$

It is important to note, that while the patients all had unilateral vestibulopathy, the degree of vestibular function remaining varied, and this information was not available for all patients. That being said, there were no significant outliers among the patients in our results, suggesting that while the vestibular function may have varied between patients, the overall impact on stability control was reasonably consistent. This was not a concern for our results, as we treated these subjects as a generalized group with balance disorders that should be distinct from healthy subjects in terms of stability and balance control.

In conclusion, no consistently significant relationship between posturography and the trip recovery task measures was found, indicating that different mechanisms of postural control appear to be involved in our static and dynamic stability tasks. Balance maintenance during quiet stance alone may be of limited use in predicting dynamic stability during perturbed walking. We therefore recommend that task specificity should be considered in clinical and research settings regarding stability and falls risk assessment. Future research should aim to relate laboratory-induced gait perturbation outcomes with real-life falls.

\section{Acknowledgments}

Financial support from the Forschungsservicestelle, German Sport University Cologne (Hochschulinterne Forschungsförderung) is greatly appreciated. CM was funded by the Kootstra Talent Fellowship awarded by the Centre for Research Innovation, Support and Policy (CRISP) of Maastricht University Medical Center+ and by the NUTRIM Graduate Programme of Maastricht University Medical Center+

\section{References}

1. Ku PX, Osman NAA, Abas WAW. Balance control in lower extremity amputees during quiet standing: a systematic review. Gait Posture. 2014;39(2):672-682. PubMed doi:10.1016/j.gaitpost.2013.07.006

2. Lord SR, Sherrington C, Menz HB, Close JCT. Falls in Older People: Risk Factors and Strategies for Prevention. 2nd ed. New York, USA: Cambridge University Press; 2011.

3. Merlo A, Zemp D, Zanda E, et al. Postural stability and history of falls in cognitively able older adults: the Canton Ticino study. Gait Posture. 2012;36(4):662-666. PubMed doi:10.1016/j.gaitpost.2012.06.016

4. Fujimoto C, Egami N, Kinoshita M, Sugasawa K, Yamasoba T, Iwasaki S. Idiopathic latent vestibulopathy: a clinical entity as a cause of chronic postural instability. Eur Arch Otorhinolaryngol. 2015;272(1):43-49. PubMed doi:10.1007/s00405-013-2834-0

5. Perez N, Santandreu E, Benitez J, Rey-Martinez J. Improvement of postural control in patients with peripheral vestibulopathy. Eur Arch Otorhinolaryngol. 2006;263(5):414-420. PubMed doi:10.1007/ s00405-005-1027-x

6. Pavlou M, Quinn C, Murray K, Spyridakou C, Faldon M, Bronstein AM. The effect of repeated visual motion stimuli on visual dependence and postural control in normal subjects. Gait Posture. 2011;33(1):113-118. PubMed doi:10.1016/j.gaitpost.2010.10.085

7. Dettmer M, Pourmoghaddam A, O'Connor DP, Layne CS. Interaction of support surface stability and Achilles tendon vibration during a postural adaptation task. Hum Mov Sci. 2013;32(1):214-227. PubMed doi:10.1016/j.humov.2012.12.002

8. Kanakis I, Hatzitaki V, Patikas D, Amiridis IG. Postural leaning direction challenges the manifestation of tendon vibration responses at the ankle joint. Hum Mov Sci. 2014;33:251-262. PubMed doi:10.1016/j. humov.2013.09.005

9. Thompson C, Belanger M, Fung J. Effects of plantar cutaneo-muscular and tendon vibration on posture and balance during quiet and perturbed stance. Hum Mov Sci. 2011;30(2):153-171. PubMed doi:10.1016/j. humov.2010.04.002

10. Berg WP, Alessio HM, Mills EM, Tong C. Circumstances and consequences of falls in independent community-dwelling older adults. Age Ageing. 1997;26(4):261-268. PubMed doi:10.1093/ageing/26.4.261

11. Blake AJ, Morgan K, Bendall MJ, et al. Falls by elderly people at home: prevalence and associated factors. Age Ageing. 1988;17(6):365-372. PubMed doi:10.1093/ageing/17.6.365

12. Kelsey JL, Procter-Gray E, Hannan MT, Li W. Heterogeneity of falls among older adults: implications for public health prevention. Am J Public Health. 2012;102(11):2149-2156. PubMed doi:10.2105/ AJPH.2012.300677 
13. Niino N, Tsuzuku S, Ando F, Shimokata H. Frequencies and circumstances of falls in the National Institute for Longevity Sciences, Longitudinal Study of Aging (NILS-LSA). J Epidemiol. 2000;10(Suppl 1):S90-S94. PubMed doi:10.2188/jea.10.1sup_90

14. Talbot LA, Musiol RJ, Witham EK, Metter EJ. Falls in young, middleaged and older community dwelling adults: perceived cause, environmental factors and injury. BMC Public Health. 2005;5:86. PubMed doi:10.1186/1471-2458-5-86

15. Kingma H, Gauchard GC, de Waele C, et al. Stocktaking on the development of posturography for clinical use. J Vestib Res. 2011;21(3):117125. PubMed

16. Maki BE, McIlroy WE. Control of rapid limb movements for balance recovery: age-related changes and implications for fall prevention. Age Ageing. 2006;35(Suppl2):ii12-ii18. PubMed doi:10.1093/ageing/afl078

17. McCrum C, Eysel-Gosepath K, Epro G, et al. Deficient recovery response and adaptive feedback potential in dynamic gait stability in unilateral peripheral vestibular disorder patients. Physiol Rep. 2014;2(12):e12222. PubMed doi:10.14814/phy2.12222

18. Patel P, Bhatt T. Adaptation to large-magnitude treadmill-based perturbations: improvements in reactive balance response. Physiol Rep. 2015;3(2):e12247. PubMed doi:10.14814/phy2.12247

19. Pijnappels M, Bobbert MF, van Dieën JH. Push-off reactions in recovery after tripping discriminate young subjects, older non-fallers and older fallers. Gait Posture. 2005;21(4):388-394. PubMed doi:10.1016/j. gaitpost.2004.04.009

20. Bhatt T, Espy D, Yang F, Pai YC. Dynamic gait stability, clinical correlates, and prognosis of falls among community-dwelling older adults. Arch Phys Med Rehabil. 2011;92(5):799-805. PubMed doi:10.1016/j. apmr.2010.12.032

21. Mackey DC, Robinovitch SN. Postural steadiness during quiet stance does not associate with ability to recover balance in older women. Clin Biomech (Bristol, Avon). 2005;20(8):776-783. PubMed doi:10.1016/j. clinbiomech.2005.05.002

22. Owings TM, Pavol MJ, Foley KT, Grabiner MD. Measures of postural stability are not predictors of recovery from large postural disturbances in healthy older adults. J Am Geriatr Soc. 2000;48(1):42-50. PubMed doi:10.1111/j.1532-5415.2000.tb03027.x

23. Homann B, Plaschg A, Grundner M, et al. The impact of neurological disorders on the risk for falls in the community dwelling elderly: a case-controlled study. BMJ Open. 2013;3(11):e003367. PubMed doi:10.1136/bmjopen-2013-003367

24. Lüscher M, Theilgaard S, Edholm B. Prevalence and characteristics of diagnostic groups amongst 1034 patients seen in ENT practices for dizziness. J Laryngol Otol. 2014;128:128-133. PubMed

25. Neuhauser HK, Von Brevern M, Radtke A, et al. Epidemiology of vestibular vertigo: a neurotologic survey of the general population. Neurology. 2005;65(6):898-904. PubMed doi:10.1212/01. wnl.0000175987.59991.3d

26. Terroso M, Rosa N, Marques AT, Simoes R. Physical consequences of falls in the elderly: a literature review from 1995 to 2010. Eur Rev Aging Phys Act. 2014;11(1):51-59. doi:10.1007/s11556-013-0134-8
27. Borello-France DF, Gallagher JD, Redfern M, Furman JM, Carvell GE. Voluntary movement strategies of individuals with unilateral peripheral vestibular hypofunction. J Vestib Res. 1999;9(4):265-275. PubMed

28. Raptis HA, Dannenbaum E, Paquet N, Feldman AG. Vestibular system may provide equivalent motor actions regardless of the number of body segments involved in the task. J Neurophysiol. 2007;97(6):4069-4078. PubMed doi:10.1152/jn.00909.2006

29. El-Kahky AM, Kingma H, Dolmans M, de Jong I. Balance control near the limit of stability in various sensory conditions in healthy subjects and patients suffering from vertigo or balance disorders: impact of sensory input on balance control. Acta Otolaryngol. 2000;120(4):508-516. PubMed doi:10.1080/000164800750046018

30. Aoki M, Tokita T, Kuze B, Mizuta K, Ito Y. A characteristic pattern in the postural sway of unilateral vestibular impaired patients. Gait Posture. 2014;40(3):435-440. PubMed doi:10.1016/j.gaitpost.2014.05.013

31. Balaguer García RB, Corresa SP, Bertomeu JMB, Suárez-Varela MMM. Static posturography with dynamic tests. usefulness of biomechanical parameters in assessing vestibular patients. Acta Otorrinolaringol Esp. 2012;63(5):332-338. PubMed doi:10.1016/j. otoeng.2012.09.003

32. Yeh JR, Lo MT, Chang FL, Hsu LC. Complexity of human postural control in subjects with unilateral peripheral vestibular hypofunction. Gait Posture. 2014;40(4):581-586. PubMed doi:10.1016/j. gaitpost.2014.06.016

33. Eysel-Gosepath K, McCrum C, Epro G, Brüggemann GP, Karamanidis K. Visual and proprioceptive contributions to postural control of upright stance in unilateral vestibulopathy. Somatosens Mot Res. 2016;33(2):72-78. PubMed

34. Allum JH, Tang KS, Carpenter MG, Oude Nijhuis LB, Bloem BR. Review of first trial responses in balance control: influence of vestibular loss and Parkinson's disease. Hum Mov Sci. 2011;30(2):279_ 295. PubMed doi:10.1016/j.humov.2010.11.009

35. McCrum C, Epro G, Meijer K, Zijlstra W, Brüggemann G-P, Karamanidis K. Locomotor stability and adaptation during perturbed walking across the adult female lifespan. J Biomech. 2016;49(7):12441247. PubMed doi:10.1016/j.jbiomech.2016.02.051

36. Süptitz F, Catala MM, Brüggemann GP, Karamanidis K. Dynamic stability control during perturbed walking can be assessed by a reduced kinematic model across the adult female lifespan. Hum Mov Sci. 2013;32(6):1404-1414. PubMed doi:10.1016/j. humov.2013.07.008

37. Dempster WT, Gabel WC, Felts WJ. The anthropometry of the manual workspace for the seated subject. Am J Phys Anthropol. 1959;17:289-317. PubMed doi:10.1002/ajpa.1330170405

38. Hof AL, Gazendam MG, Sinke WE. The condition for dynamic stability. J Biomech. 2005;38(1):1-8. PubMed doi:10.1016/j.jbiomech.2004.03.025 